\title{
CARCINOMA ESPINOCELULAR: REPORTE DE CASO EN PACIENTE CON FOTOTIPO TIPO 5 SEGÚN CLASIFICACIÓN FITZPATRICK
}

\author{
PETTY BONIVENTO JOHNSSON ${ }^{1}$, GUILLERMO TROUT GUARDIA ${ }^{2}$, \\ JAMITH MAESTRE GARZÓN, MAYRA MUÑOZ VERGARA³, \\ MARÍA CAROLINA MORENO OCHOA ${ }^{3}$ \\ ${ }^{1}$ Médico-Dermatóloga. Docente de Planta, Universidad del Magdalena. Santa Marta. Colombia. \\ ${ }^{2}$ Medico-Cardiólogo. Decano de la Facultad de Ciencias de la Salud, \\ Universidad del Magdalena. Santa Marta Colombia \\ ${ }^{3}$ Médico General, Universidad del Magdalena. Santa Marta. Colombia. \\ Correspondencia: María Carolina Moreno Ochoa \\ mariacarolinamorenoochoa@gmail.com
}

Recibido: 2 de abril de 2017 Aceptado: 5 de junio de 2018

\begin{abstract}
Resumen
El carcinoma espinocelular es un subtipo de neoplasia que no involucra a los melanocitos, y junto con el carcinoma basocelular, representan el $75 \%$ de los carcinomas de piel no melanoma. En Colombia, se calculó que de 2003 a 2007 el cáncer no melanoma registró un incremento de 19 a 39 casos por 100000 habitantes. El carcinoma espinocelular tiende a aparecer en fototipos de piel 1 y 2, en áreas fotoexpuestas que representan cabeza y cuello (70\%), en extremidades superiores (25\%) y en zonas no fotoexpuetas como glúteos y mucosas genitales (5\%). Este artículo hace un reporte de caso de un carcinoma espinocelular en un paciente de 51 años con un cuadro clínico aproximadamente de dos años que se caracterizó por diversos tumores localizados en labio inferior derecho y maxilar inferior y que estuvo relacionado a exposición solar crónica y presencia de queratosis actínica en cara y cuero cabelludo.
\end{abstract}

Palabras clave: carcinoma escamocelular; queratinocitos; cáncer de piel; neoplasia 


\title{
NON-MELANOMA SKIN CARCINOMA: SPINOCELLULAR CARCINOMA, CASE REPORT IN A PATIENT WITH TYPE 5 PHOTOTYPE ACCORDING TO FITZPATRICK CLASSIFICATION
}

\begin{abstract}
Spinocellular carcinoma is a subtype of neoplasia that does not involve melanocytes, and together with basal cell carcinoma, they represent $75 \%$ of non-melanoma skin carcinomas. In Colombia, it was calculated that from 2003 to 2007 non-melanoma cancer registered an uptick of 19 to 39 cases per 100,000 inhabitants. Spinocellular carcinoma tends to appear in skin phototypes 1 and 2, in photoexposed areas that represent head and neck (70\%), in upper extremities (25\%) and in non-photoexposed areas such as buttocks and genital mucous membranes (5\%). This article makes a case report of a spinocellular carcinoma in a 51-year-old patient with a clinical picture of approximately two years that was characterized by various tumors located in the right lower lip and lower jaw related to chronic sun exposure and presence of actinic keratosis on face and scalp.
\end{abstract}

Keywords: squamous cell carcinoma; keratinocytes; skin cancer; neoplasia.

\section{CARCINOMA DE PELE NÃO MELANOMA: CARCINOMA ESPINOCELULAR, RELATO DE CASO EM PACIENTE COM FOTOTIPO V SEGUNDO CLASSIFICAÇÃO FITZPATRICK}

\begin{abstract}
Resumo
O carcinoma espinocelular é um subtipo de neoplasia que não envolve os melanócitos, e junto com o carcinoma basocelular, representam 75\% dos carcinomas de pele não melanoma. Na Colômbia, calculou-se que de 2003 a 2007 o câncer não melanoma registrou um aumento de 19 a 39 casos por 100000 habitantes. O carcinoma espinocelular tende a aparecer em fototipos de pele I e II, em áreas fotoexpostas que representam cabeça e pescoço (70\%), em extremidades superiores (25\%) e em áreas não fotoexpostas como glúteos e mucosas genitais (5\%). Este artigo faz um relato de caso de um carcinoma espinocelular num paciente de 51 anos com um quadro clínico aproximadamente de dois anos que se caracterizou por diversos tumores localizados em lábio inferior direito e maxilar inferior e que esteve relacionado à exposição solar crônica e presença de ceratose actínica na cara e no couro cabeludo.
\end{abstract}

Palavras-chave: carcinoma escamocelular; queratinocitos; câncer de pele; neoplasia. 


\section{Introducción}

El carcinoma espinocelular es un subtipo de neoplasia que no involucra a los melanocitos denominada cáncer de piel no melanoma (CPNM). Junto con el carcinoma basocelular representan un 75\% de los CPNM (1). La incidencia de carcinoma espinocelular global fue de 387 por 100 000 hab. (2-3). Para Colombia se calculó que en el periodo de 2003 a 2007 el cáncer no melanoma pasó de 19 a 39 casos por 100000 hab., lo que muestra un aumento exponencial en la aparición de la enfermedad. El carcinoma espinocelular causó 137 muertes en los años comprendidos entre 2004 y 2010, teniendo en cuenta que los registros de cáncer no melanoma que sustentan estas cifras son solo los registrados por el Instituto Nacional de Cancerología (4). La fisiopatología del cáncer no melanoma es la mutación del p53 y del p16 (5-6), además en los últimos años se han desarrollado nuevos estudios que sugieren que las células madres epidérmicas por inflamación migran a la medula ósea pudiendo repoblar después de muchos años la epidermis de nuevo y producir cáncer no melanoma (7). Se han involucrado dianas moleculares como PTEN, AKT, RAD-51, entre muchos otros, en la aparición del carcinoma espinocelular (8). El carcinoma espinocelular prolifera con rapidez y es proclive a hacer metástasis, y su precursor precanceroso es la queratosis actínica en zonas expuestas a la luz del sol, su progresión a carcinoma espinocelular es del 0,25 al $20 \%$, y de estos pueden enviar metástasis del 0,3 al 5\% (9). El tratamiento se encaminará a la mayor preservación cosmética posible y la intervención terapéutica irá encaminada según la localización del tumor, ulceración, infiltración de ganglios, extensión total, etc. (10-12).

\section{Presentación del caso}

Paciente masculino de 51 años, natural del municipio de Sitionuevo, departamento del Magdalena, dedicado a la pesca, remitido del Hospital de Ciénaga al Hospital Universitario Fernando Troconis (HUFT) en la ciudad de Santa Marta en octubre de 2015. Presenta un cuadro clínico de aproximadamente dos años de evolución, el cual inicia con la aparición en el labio inferior derecho de vesículas de contenido líquido, no viscoso acompañado de prurito, la lesión evolucionó a nódulo y, en el transcurso de un año y nueve meses, se convierte en un tumor de $0,03 \mathrm{~m}(3 \mathrm{~cm})$ de diámetro aproximadamente, de bordes irregulares, superficie nodular, con úlcera de bordes elevados y fondo granuloso con regiones necróticas y que en ocasiones presentaba sangrado (figuras 1 y 2 ). Posteriormente aparece lesión de aproximadamente 0,1 $\mathrm{m}(10 \mathrm{~cm})$ de diámetro, con características crateriformes localizadas en región maxilar inferior, de superficie lisa, con múltiples nódulos y con úlcera ubicada centralmente, de bordes elevados y fondo granuloso que se acompaña de prurito (figura 3 ).

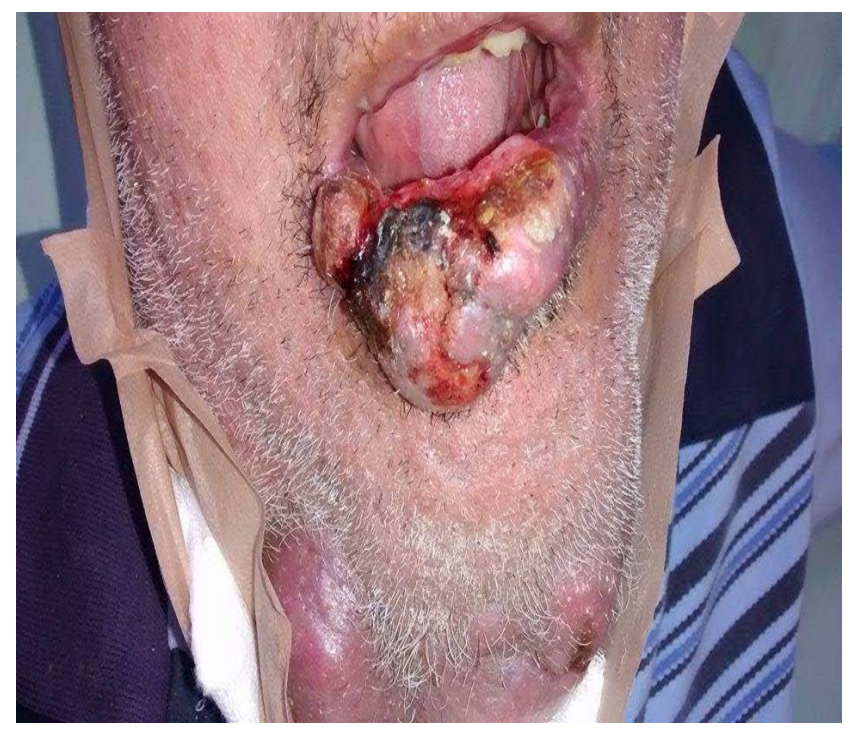

Figura 1. Vista frontal. Tumor localizado en labio inferior cercano a la comisura labial derecha.

Fuente: Fotografía de los autores.

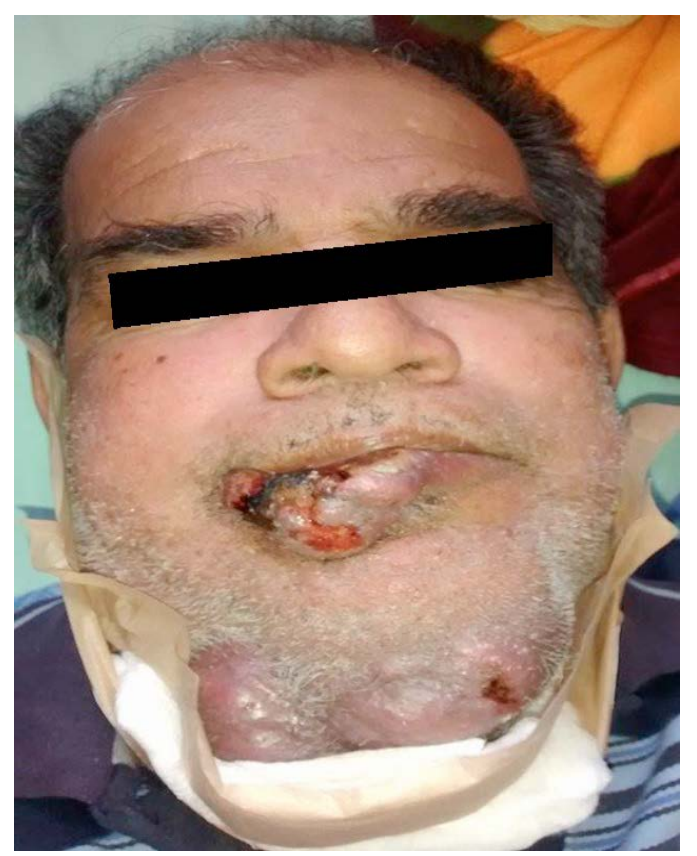

Figura 2. Vista frontal. Tumor localizado en labio inferior y región maxilar inferior; este último cubierto por apósitos.

Fuente: Fotografía de los autores. 


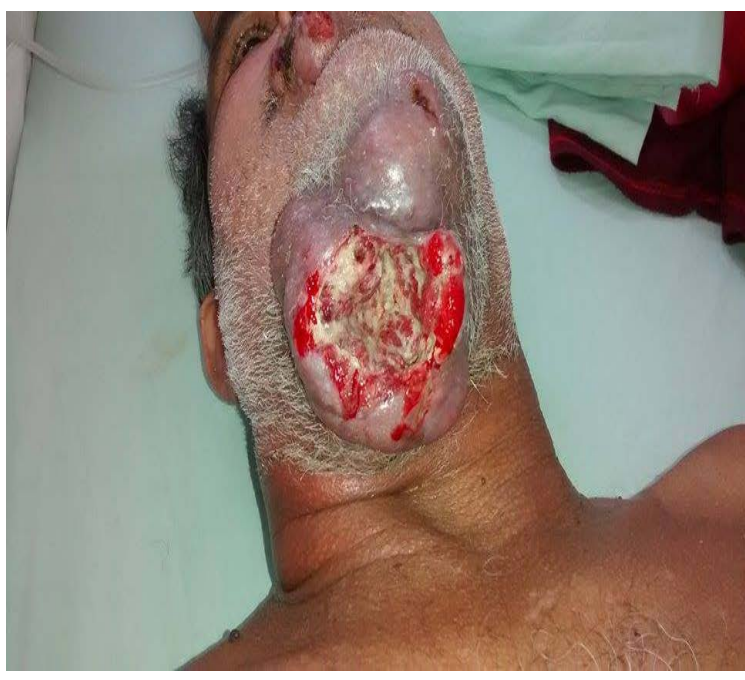

Figura 3. Vista inferior. Tumor ubicado en región maxilar inferior donde se aprecia con claridad la ulceración de bordes elevados y fondo granuloso.

Fuente: Fotografía de los autores.

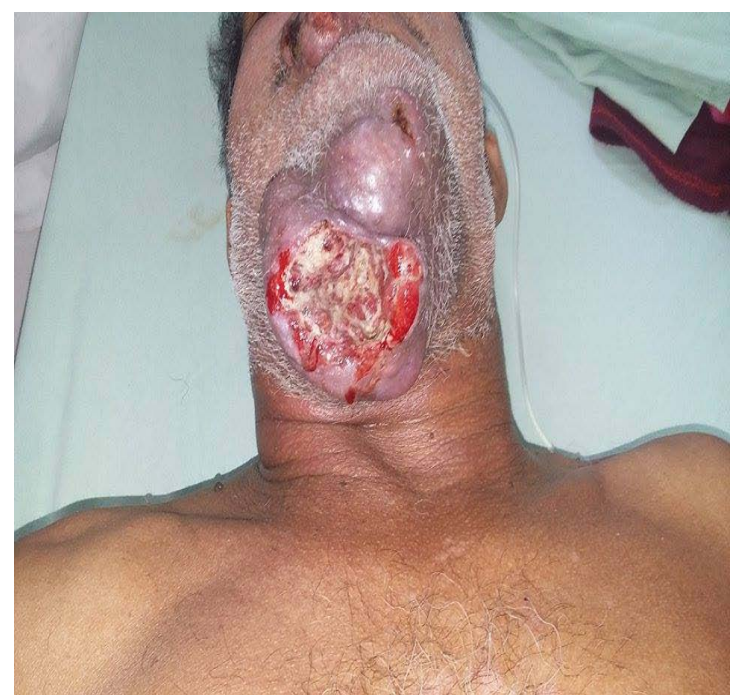

Figura 4. Vista inferior. Tumor ubicado en región maxilar inferior, máculas hipocrómicas de bordes definidos localizadas en tronco anterior.

Fuente: Fotografía de los autores.

$\mathrm{Al}$ interrogatorio, el paciente no indicó antecedentes de enfermedades crónicas; dentro de los antecedentes psicosociales de importancia, existe una exposición crónica a la luz solar, índice tabáquico de dos paquetes año, no indica consumo previo ni actual de sustancias psicoactivas, ni de bebidas alcohólicas. Al examen físico, el paciente se encontraba en decúbito supino, y con edad aparente acorde con la edad cronológica, con buen estado nutricional, orientado en espacio, tiempo y persona. Los signos vitales: frecuencia cardiaca 100 latidos por minuto, frecuencia respiratoria 20 respiraciones por minuto, presión arterial $120 / 80 \mathrm{mmHg}$, temperatura $37^{\circ} \mathrm{C}$, peso $64 \mathrm{~kg}$, talla $1,70 \mathrm{~m}$, IMC 22,15 (peso normal); evaluación pulmonar, cardiovascular y de abdomen sin alteraciones.

Dentro de las ayudas diagnósticas que fueron realizadas al paciente, se le practicó una biopsia y una tomografía axial computarizada. Los resultados de la biopsia incisional de labio inferior y encía libre reportó carcinoma escamoso infiltrante bien diferenciado acompañado de material queratínico y detritos celulares; la descripción macroscópica detalla tres fragmentos irregulares pardos grisáceos que miden $0,005 \mathrm{~m}(0,5 \mathrm{~cm})$ y $0,006 \mathrm{~m}$ $(0,6 \mathrm{~cm}) \times 0,003 \mathrm{~m}(0,3 \mathrm{~cm})$. La descripción microscópica indicó que se observaron fragmentos mayores histológicos de tejido conectivo con neoformaciones de células escamosas atípicas distribuidas formando nidos e islotes tumorales que presentan células de citoplasma amplio acidófilo, núcleo de cromática laxa, con nucléolo y otros núcleos hipercromáticos, formación de perlas con globos correos, con células disqueratócicas. Los fragmentos menores presentan material queratínico con eritrocitos en el que se aprecian núcleos de nudos con detritos neutrofílicos. La tomografía axial computarizada con reconstrucción tridimensional reportó cambios inflamatorios de la mucosa y quistes de retención en el antro maxilar izquierdo, ligero engrosamiento en la mucosa del conducto lacrimonasal izquierdo, el septo nasal levemente desviado hacia la derecha, engrosamiento en la mucosa de los cornetes medios e inferior, con reducción de la amplitud de la columna aérea de las fosas nasales, por cambios hipertróficos versus rinitis, lesión de aspecto ocupante e infiltrante que compromete los tejidos blandos del labio inferior, en territorio paramedial derecho de aproximadamente $0,036 \mathrm{~m}(36 \mathrm{~mm}) \times 0,021 \mathrm{~m}(21 \mathrm{~mm})$ de estirpe histológica a determinar y tenue refuerzo de la lesión ocupante descrita en el labio inferior derecho.

Posteriormente, las lesiones en el cuello del paciente realizaron metástasis hasta mediastino y pulmón, lo cual conllevó falla ventilatoria, por lo que el paciente requirió asistencia en unidad de cuidados intensivos (UCI). Sin embargo, la infiltración llevó a derrames pleurales masivos, a los cuales se les dio manejo con ventilación mecánica invasiva. Finalmente, el paciente, debido a todas las complicaciones ocasionadas por el carcinoma epidermoide, tuvo un desenlace fatal. 
A) Tomografía computariza (TC) del maxilar inferior: corte axial.

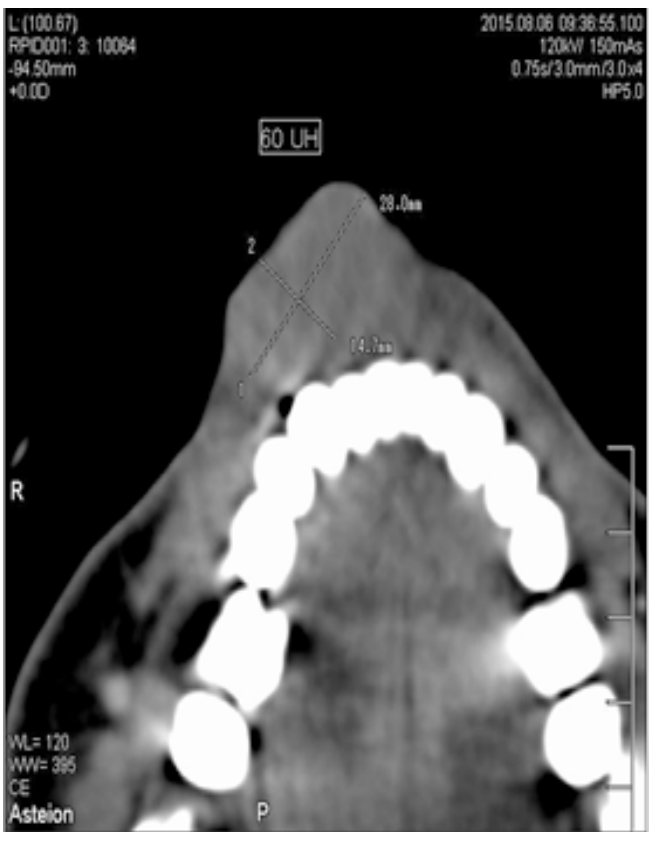

B) TC corte coronal.

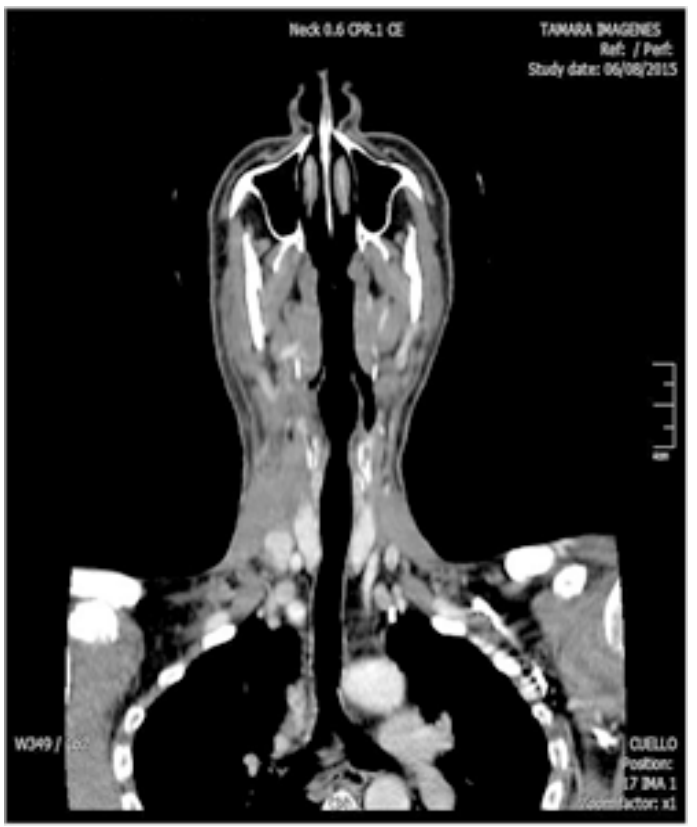

C) TC corte coronal.

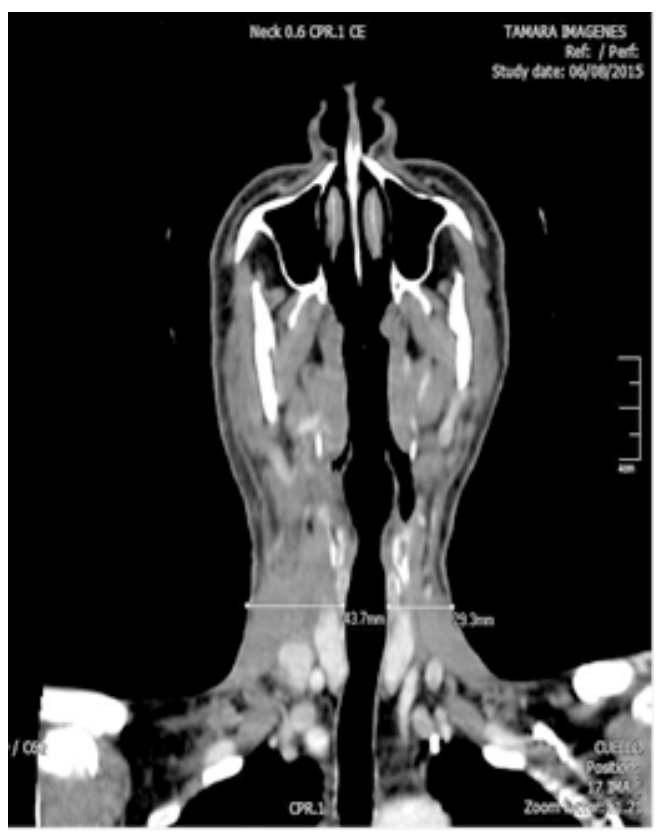

D) TC corte sagital.

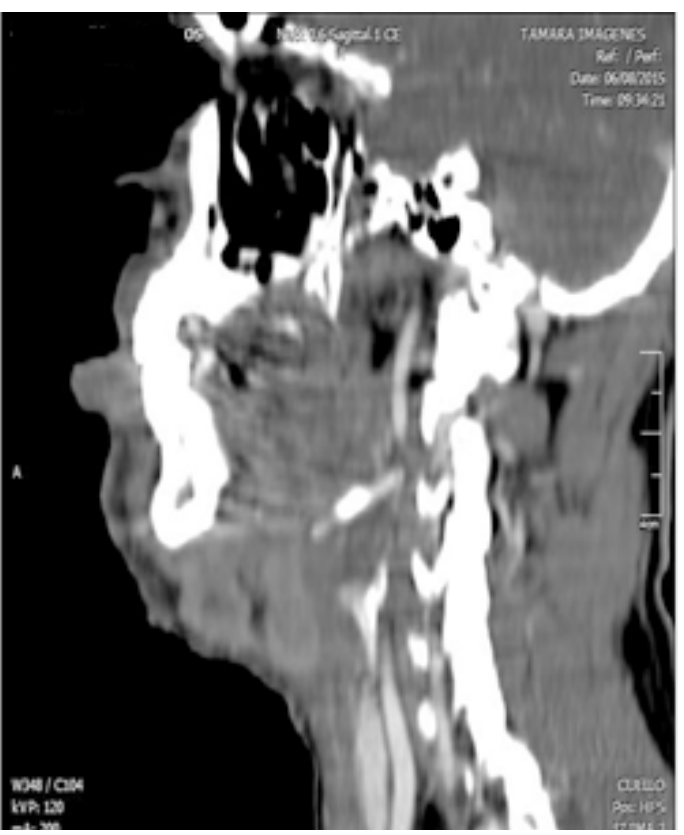

Figura. 5. A) Tomografía computariza (TC) del maxilar inferior: corte axial. Lesión de aspecto nodular que compromete tejido blando inferior derecho de $36 \times 21$ de diámetro y realza en forma homogénea luego de la aplicación de medio de contraste. Sin compromiso óseo. B y C) TC corte coronal. En la reconstrucción coronal, se observa aumento de la densidad y grosor de los tejidos blandos del cuello en el lado derecho, no pudiéndose diferenciar satisfactoriamente la presencia de adenomegalia. D) TC corte sagital. En la reconstrucción sagital, se evidenciaron formaciones redondeadas submandibulares que podrían ser compatibles con adenomegalia en el nivel 1 y 2 de los ganglios del cuello.

Fuente: Fotografías de los autores. 


\section{Discusión y conclusión}

El carcinoma espinocelular ha aumentado dos veces su prevalencia durante los últimos cuarenta años. Esto se cree que es principalmente por el deterioro de la capa de ozono, las campañas publicitarias que han sensibilizado a la población y la inmunosupresión fuerte aumenta 65 veces el riesgo para desarrollar carcinoma espinocelular (14). El carcinoma espinocelular tiende a aparecer en fototipos 1 y 2 , y es menos frecuente en los demás fototipos. El paciente del presente reporte de caso tiene un fototipo de piel 5 , pero con un antecedente importante de exposición solar crónica de más de treinta años debido a su oficio (pescador), lo cual desempeñó un papel fundamental en la génesis del tumor. El precursor de carcinoma espinocelular que presentaba nuestro paciente era la queratosis actínica que se caracteriza por máculas o pápulas de superficie áspera de bordes mal definidos y con una base eritematosa. El riesgo de metástasis aumenta en el sexo masculino y aparece en el labio inferior, aunque los carcinomas espinocelulares intraorales tienen peor pronóstico que estos. Las guías actuales sugieren la escisión completa del tumor $(15,16-17)$.

No obstante, la exposición prolongada a la luz solar no se constituye como el único y exclusivo factor de riesgo para esta enfermedad, sin embargo, representa la más relevante del caso expuesto. En este sentido, uno de los factores de riesgo que también se relaciona con el desarrollo de carcinoma espinocelular es el tabaquismo, el cual está asociado, no solo a las lesiones en la piel, sino también en las mucosas, de modo que estas son más propensas a hacer metástasis y de peor pronóstico. También se puede incluir entre los factores de riesgo la residencia en áreas rurales, no solo debido a que hay una mayor exposición a la radiación ultravioleta, sino porque esta población tiene una gran tendencia a la no prevención a la exposición solar mediante el uso de medidas de protección, hecho que guarda estrecha relación con factores como la educación, el acceso a las comunicaciones, el ingreso y la raza.

La literatura sugiere que es de suma importancia detectar de manera temprana ciertos hallazgos de daño solar al realizar el examen físico, tales como lentigo, poiquilodermia, efélides y queratosis actínica, con el fin de llevar un seguimiento estricto de estos pacientes para hacer un diagnóstico precoz del carcinoma espinocelular (30).

La distribución corporal del carcinoma espinocelular se presenta de la siguiente manera: cara $(67,6 \%)$, extremidades $(20 \%)$, cuero cabelludo $(4,8 \%)$, genitales $(3,6 \%)$, tronco $(2,1 \%)$ y cuello $(1,9 \%)(25)$. Específicamente en la cara, la distribución más frecuente es de la siguiente manera: mejillas $(23,8 \%)$, nariz $(13,8 \%)$, frente $(9,7 \%)$, labios bermellón $(7,3 \%)$ y auricular $(5,2 \%)(26)$.

La séptima clasificación del Comité Conjunto Estadounidense sobre el Cáncer especificó como lugares de alto riesgo de carcinoma espinocelular el labio y el pabellón auricular, ya que estas regiones carecen de mucho tejido celular subcutáneo y tienen una rica vascularización (27).

En cuanto al manejo del paciente, la estatificación, según el American Joint Committee on Cancer (AJCC), recomienda la biopsia de ganglio centinela, ya que ha demostrado ser segura y altamente específica y sensible. Esta no se realizó en el paciente de este artículo, ocultando la invasividad del tumor $(18,19,20)$ cuando el tumor es estadificación $\mathrm{b}$ (tumor de $2 \mathrm{~cm}$ y pobremente diferenciado), el $12,3 \%$ de las biopsias fueron positivas para la diseminación ganglionar (21), se sabe actualmente que el $80 \%$ de pacientes con infiltración ganglionar progresarán a metástasis (22-24) sobre todo a hígado, pulmones, cerebro o huesos, sabiendo que una gran proporción de pacientes con diseminación ganglionar evolucionarán a metástasis, una intervención de disección agresiva, realizando vaciamientos de ganglios en la región del cuello evitaría diseminación de la neoplasia a estructuras vitales (22-23).

En lo que respecta al paciente del caso actualmente reportado, quien presentaba una lesión que ya comprometía el maxilar inferior, con hallazgos tomográficos de formaciones redondeadas submandibulares compatibles con adenomegalia en el nivel 1 y 2 de los ganglios del cuello, pero sin evidencia inicial de metástasis, este pudo ser clasificado como un paciente en estadio III del carcinoma espinocelular. Sin embargo, cabe aclarar que, en función de su rápida evolución, en cuestión de aproximadamente dos meses, tuvo un desenlace en estadio IV, puesto que presentaba metástasis a distancia (27).

Clayman et al. (28) demostraron que las lesiones mayores de $4 \mathrm{~cm}$ con invasión perineural y del tejido celular subcutáneo pueden ser categorizadas como de alto riesgo por el aumento de la mortalidad. En los pacientes que presentan estas lesiones, la supervivencia a los 60 meses de seguimiento se reduce en un $40 \%$ en comparación con aquellos que presentan tumores menores de $4 \mathrm{~cm}$, sin invasión perineural y también sin penetración en el tejido celular subcutáneo, aunque la mortalidad exacta no se sabe aún porque hay datos inadecuados de su incidencia (29). 


\section{Conclusiones}

Las guías norteamericanas brindan una orientación para el profesional de la salud, En conclusión, aunque faltan ensayos clínicos aleatorizados para el manejo de estos pacientes. Sin embargo, en nuestro medio, es necesario seguir mejorando la atención de estos pacientes, realizando una buena historia clínica, efectuarles las ayudas diagnósticas pertinentes a la evolución y las características propias de la lesión, y de ser necesario, derivar a un centro especialista donde cuenten con personal especializado que le permita al individuo poder recibir una atención lo más integral posible para la resolución o el manejo paliativo de su enfermedad para evitar las complicaciones ya mencionadas.

Resaltamos la importancia de que el clínico tenga las competencias académicas para sospechar desde indicios tempranos signos y síntomas de alarma que pueden estar asociados a condiciones precancerígenas, como la queratosis actínica en este tipo de carcinomas, para evitar cirugías radicales que podrían poner en peligro la vida del paciente o afectar su estética y autoestima de manera considerable.

\section{Declaración de fuentes de financiación y posible conflicto de interés}

Los autores y coautores del presente manuscrito declaran no tener conflicto de interés de ningún tipo, ni haber recibido fuentes de financiación ya sea a través de becas, subvenciones, asistencia administrativa, equipos, programas de computación, reactivos, medicamentos, etc., por parte de universidades, instituciones o empresas aportantes públicas o privadas, para la elaboración del siguiente manuscrito.

\section{Referencias}

1. Yengle MA. Cáncer de piel no melanoma. Dermatol Peru. 2014;24(2):132-140.

2. Holme SA, Malinovszky K, Roberts DL. Changing trends in non melanoma skin cancer in South Wales, 1988-98. Br J Dermatol. 2000;143(6):1224-1229.

3. Lomas A, Leonardi-Bee J, Bath-Hextall F. A systematic review of worldwide incidence of nonmelanoma skin cancer. Br J Dermatol. 2012;166(5):1069-1080.

4. Cormane, J, Rodelo, A. Epidemiología no melanoma en Colombia. Rev Asoc Colomb Dermatol. 2014;22(1):20-26.

5. Lauth $M$, Unden $A B$, Toftgård R. Nonmelanoma skin cancer: pathogenesis and mechanisms. Drug Discov Today Dis Mech. 2004;1(2):267-72.
6. Bowden GT. Prevention of non-melanoma skin cancer by targeting ultraviolet-B-light signalling. Nat Rev Cancer. 2004;4(1):23-35.

7. Morris R. A novel mechanism for the pathogenesis of nonmelanoma skin cancer resulting from early exposure to ultraviolet light [internet]. 2013 [citado 2018 febr 27]. Disponible en: https://apps.dtic.mil/docs/citations/ AD1005069

8. Kim Y, He Y-Y. Ultraviolet radiation-induced non-melanoma skin cancer: Regulation of DNA damage repair and inflammation. Genes Dis [internet]. 2014 dic [citado 2015 sept 25];1(2):188-98. Disponible en: https://www.sciencedirect.com/science/article/pii/S2352304214000178

9. Su, F., Viros, A., Milagre, et al. RAS Mutations in Cutaneous Squamous-Cell Carcinomas in Patients Treated with BRAF Inhibitors. N Engl J Med. 2012;366(3):207-15.

10. Urba WJ, Washington CV, Nadiminti H. Cáncer de piel. En: Longo DL, Kasper DL, Jameson JL, et al., editor. Harrison principios de medicina interna. Vol 1. 18. ${ }^{\mathrm{a}}$ ed. México: McGraw-Hill; 2012. p. 723-732.

11. Rigel, D. S. Cutaneous ultraviolet exposure and its relationship to the development of skin cancer. J Am Acad Dermatol. 2008;58(5):S129-S132.

12. Garavis J. Precáncer y cáncer cutáneo II. Semergen. 2003;29(10):532-541.

13. Firnhaber JM. Diagnosis and treatment of basal cell and squamous cell carcinoma. Am Fam Physician. 2012;86(2):161-8.

14. Jensen P, Hansen S, Møller B, et al. Skin cancer in kidney and heart transplant recipients and different long-term immunosuppressive therapy regimens. J Am Acad Dermatol. 1999;40(2):177-186.

15. Hernández Martín, Á, Echevarría Iturbe, C. Carcinoma espinocelular. Piel. 2003;18(7):364-376.

16. Fu W, Cockerell CJ. The actinic (solar) keratosis: a 21stcentury perspective. Arch Dermatol. 2003;139(1):66-70.

17. Neville BW, Day TA. Oral cancer and precancerous lesions. CA Cancer J Clin 2002;52(4):195-215.

18. Wagner JD, Evdokimow DZ, Weisberger E, et al. Sentinel node biopsy for high-risk nonmelanoma cutaneous malignancy. Arch Dermatol. 2004;140(1):75-79.

19. Ross AS, Schmults CD. Sentinel lymph node biopsy in cutaneous squamous cell carcinoma: a systematic review of the english literature. Dermatol Surg. 2006;32(11):13091321.

20. Martinez JC, Cook JL. High-risk cutaneous squamous cell carcinoma without palpable lymphadenopathy: is there a therapeutic role for elective neck dissection? Dermatol Surg. 2007;33(4):410-420.

21. Schmitt AR, Brewer JD, Bordeaux JS, et al. Staging for cutaneous squamous cell carcinoma as a predictor of sentinel lymph node biopsy results: meta-analysis of American Joint Committee on Cancer criteria and a proposed alternative system. JAMA Dermatology. 2014;150(1):19. 
22. American Joint Committee on Cancer. Cutaneous squamous cell carcinoma and other cutaneous carcinomas. En: Edge SB, Byrd DR, Compton CC, et al., editor. AJCC Cancer Staging Manual. 7. ${ }^{a}$ ed. Nueva York: Springer; 2010. p. 301-309.

23. Johnson TM, Rowe DE, Nelson BR, et al. Squamous cell carcinoma of the skin (excluding lip and oral mucosa). J Am Acad Dermatol. 1992;26(3):467-484.

24. Veness MJ, Palme carcinoma espinocelular, Smith M, et al. Cutaneous head and neck squamous cell carcinoma metastatic to cervical lymph nodes (nonparotid): a better outcome with surgery and adjuvant radiotherapy. Laryngoscope. 2003;113(10):1827-1833.

25. Peniche A, Peniche, J. Tumores de la piel. [internet]. 2015 [citado 2018 febr 27]. Disponible en: https://accessmedicina.mhmedical.com/Content.aspx?bookId=1537\&sectio nId $=99045990$

26. Barrón-Tapia T, Peniche-Rosadp J, Peniche-Castellanos $\mathrm{A}$, et al. Carcinoma epidermoide de piel en la población mexicana: estudio epidemiológico y clínico de 508 tumores. Rev Médica Del Hosp Gen México. 2004;67(2):71-7.
27. Nuño-González A, Vicente-Martín FJ, Pinedo-Moraleda F, et al. Carcinoma epidermoide cutáneo de alto riesgo. Actas Dermosifiliogr. 2012;103(7):567-78.

28. Clayman GL, Lee JJ, Holsinger FC, et al. Mortality risk from squamous cell skin cancer. J Clin Oncol. 2005;23(4):75965. DOI: 10.1200/JCO.2005.02.155

29. Cranmer LD, Engelhardt C, Morgan SS. Treatment of unresectable and metastatic cutaneous squamous cell carcinoma. Oncologist. 2010;15(12):1320-1328. doi: 10.1634/ theoncologist.2009-0210

30. Sánchez G, Nova J. Factores de riesgo de carcinoma espinocelular: un estudio del Centro Nacional de Dermatología de Colombia. Actas Dermosifiliogr [internet]. 2013 [citado 27 febr 2018]; 104(8):672-678. Disponible en: http:// www.actasdermo.org/es/factores-riesgo-carcinoma-espinocelular-un/articulo/S0001731013000604/ 